\title{
ENTRE A CRUZ E A ESPADA: PANORAMA HISTÓRICO DA TEOLOGIA DA LIBERTAÇÃO NA AMÉRICA LATINA
}

\section{ARTIGO ORIGINAL}

GODOY, Juliano Bernardino de ${ }^{1}$

ASSIS, Rogério de ${ }^{2}$

GODOY, Juliano Bernardino de. ASSIS, Rogério de. Entre a cruz e a espada: Panorama histórico da Teologia da Libertação na América Latina. Revista Científica Multidisciplinar Núcleo do Conhecimento. Ano 05, Ed. 05, Vol. 08, pp. 05-

${ }^{1}$ Doutorando em Educação na Universidade Metodista de Piracicaba (UNIMEP). Mestre em Educação pela Universidade Metodista de Piracicaba (UNIMEP) 2019; Linhas de Pesquisa, História e Filosofia da Educação. Licenciado em História pela UNIESP 2012. Licenciado em Bacharel em Filosofia pelo Centro Universitário Claretiano 2014/2019 (CLARETIANO). Bacharel em Teologia pelo Centro Universitário Claretiano (CLARETIANO) 2015. Licenciado em Pedagogia pelo Centro Universitário de Araras (UNAR) 2016. Licenciado em Sociologia pelo Centro Universitário de Araras (UNAR) 2018. Licenciado em Geografia a pelo Centro Universitário de Araras (UNAR) 2020.

2 Mestrado em Educação pela Universidade Nove de Julho (UNINOVE), 2019; Linha de pesquisa: Educação, Filosofia e Formação Humana (LIPEFH), integrante do Grupo de Pesquisa e Estudo em Filosofia da Educação - (GRUPEFE) e Grupo de Pesquisa e Estudo da Complexidade (GRUPEC), sob a coordenação dos Profs. Dr. Antônio Joaquim Severino e Dra. Cleide Rita Silvério de Almeida (UNINOVE). Pós-Graduação Lato Sensu em Formação de Docentes para o Ensino Superior pelo Centro Universitário Assunção (UNIFAI) 2015; Pós-Graduação em Teologia Reformada pela Missão Evangélica Literária (CFL) 2019; Bacharelado em Teologia pela Pontifícia Faculdade de Teologia Nossa Senhora da Assunção - Centro Universitário Assunção (UNIFAI) 2007; Bacharelado em Teologia pelo Instituto Anglicano de Estudos Teológicos (IAET) 2005. 
16. Maio de 2020. ISSN: 2448-0959, Link de acesso: https://www.nucleodoconhecimento.com.br/teologia/cruz-e-a-espada

\section{RESUMO}

O presente artigo aborda a Teologia da Libertação na perspectiva da América Latina com o intuito de traçar um breve panorama histórico, sua fundamentação teológica e teórica, seu momento ápice e seu arrefecimento. Além disso, pretende-se mostrar que tal movimento não é, em hipótese alguma, monopólio da Igreja Católica Romana, como muitos por puro desconhecimento pensam ser. Mostrar-se-á que tal movimento teológico fez e ainda faz parte também do mundo Protestante, de maneira mais tímida, é bem verdade, mas fato é que muitos protestantes e evangélicos abraçaram a causa de igual modo. Por fim, de acordo com os especialistas referenciados, a Teologia da Libertação ainda não morreu, permanece viva, mesmo que imperceptivelmente nos dias pós-modernos. Pensar em tais questões, dada a sua atualidade, justifica a relevância desta reflexão.

Palavras-chave: Teologia da Libertação, América-Latina, Cristologia, sociologia da religião.

\section{INTRODUÇÃO}

De forma suscinta, apresentaremos a temática da Teologia da Libertação no contexto da América Latina com o intuito de despertar o maior interesse do leitor (a) ao aprofundamento do tema. Para tal, optamos por percorrer o seguinte caminho metodológico: 1- Origem e o que é e Teologia da Libertação; 2- Pressupostos teóricos e teológicos da Teologia da Libertação; 3- Decadência e futuro da Teologia da Libertação; seguido das Considerações Finais e das devidas Referências. Com fé e esperança de que o assunto seja aprofundado a partir da semente lançada no presente artigo, nós, os autores, desejamos a você uma boa leitura e um bom proveito. Gratidão por seu interesse no assunto, afinal, em nossa opinião, de teólogos, pastores, estudiosos e eternos aprendizes, toda a Teologia é libertadora, pois ela 
promove um encontro com Deus, e, por sua vez, todo encontro com Deus é um encontro de libertação.

\section{ORIGEM E O QUE É TEOLOGIA DA LIBERTAÇÃO}

A "Teologia da Libertação", ou, em espanhol, "Teologia de la Liberación", é uma teologia que nasceu e se construiu a partir de uma análise crítica da realidade social. Com o olhar fito no rosto empobrecido de Cristo Bom Pastor, ao invés do olhar fito no rosto do Cristo Pantocrator[3], traz uma grande diferença de olhar e de ponto de vista teológico. Diferentemente da Teologia Tradicional, que parte da contemplação das realidades, digamos "celestes", a Teologia da Libertação se faz a partir das realidades terrestres, sobretudo da questão cruel da pobreza e da miséria. Trata-se, portanto, de uma Teologia feita por gente de carne e osso, com os pés no chão. O termo Teologia da Libertação foi criado pelo padre peruano Gustavo Gutierrez[4], considerado o "pai" dessa modalidade do pensar e do agir teológico. A Teologia da Libertação foi formulada a partir de um movimento dentro da Igreja Católica latino-americana, por volta dos anos 1950-60.

Nesta década, grandes acontecimentos sacudiram a sociedade e a Igreja e no bojo desses acontecimentos despertou a necessidade de um envolvimento da Igreja na questão social. Ler a realidade a partir de uma releitura do Evangelho que justificasse o engajamento dos cristãos nos problemas sociais e encarar de frente os problemas da fome, da violência, da administração da cidade e da terra eram algumas das reflexões propostas. Segundo Rodrigo Augusto Leais Camilo, estudioso da Teologia da Libertação, no decorrer do século XX, dentro da Igreja Católica, a preocupação com a questão social mereceu uma atenção toda especial no Brasil e na América Latina, em virtude da história e da grande presença católica nesta região. No Brasil, desde que o catolicismo deixou de ser a religião oficial do Estado, com a Proclamação da República, em 1889, a Igreja passou por grandes transformações.

Ainda segundo Rodrigo Augusto, os movimentos messiânicos, a falta de padres e o crescimento de outras crenças contribuíram para a reorganização da estrutura da Igreja Católica no Brasil. Neste contexto, cresceu, também, o envolvimento dos 
cristãos no cotidiano de outros fiéis, proporcionando um contexto direto com o sofrimento e as dificuldades de uma grande parcela da população. Foi nesse contexto da Igreja atenta às questões da pobreza e da opressão que nasceu o movimento da Teologia da Libertação. Acrescente-se a tudo isso o surgimento das ditaduras militares na América Latina. A Teologia da Libertação se expandiu e ganhou presença em todos os continentes como um modelo diferente de fazer teologia a partir da realidade social dos pobres.

Segundo Leonardo Boff: "os pobres foram condenados porque cometeram um crime inaceitável: apoiar aqueles que estão fora do mercado e zero econômico" (BOFF, 2011 , p. 12). A hierarquia católica a condenou por cair numa "heresia" prática ao afirmar que o pobre pode ser construtor de uma nova sociedade e de um novo modelo de Igreja. Naturalmente e infelizmente, muitos foram os religiosos e religiosas silenciados pela cúpula católica, dentre eles o próprio Leonardo Boff, na época frade franciscano. Todavia e para surpresa de muitos, não apenas a Igreja Católica silenciou os seus, mas também outras Igrejas históricas o fizeram, tal como se pode ler nesta breve citação de João Dias de Araújo com relação à Igreja Presbiteriana.

Esse golpe contra a jovem imprensa presbiteriana foi uma reação às declarações ousadas e verdadeiras que culminaram com o número de junho de 1960. Para dar apenas um exemplo desse número: o jovem Paulo Wright escreve o artigo 'O Senhor do Mundo', no qual tratou da ação de Cristo na Igreja e no mundo e a consequente liberdade para o cristão testemunhar. No final do artigo declarou: 'O problema não é mais se dançar ou não dançar, se fumar ou não fumar é pecado, pois sendo Jesus nosso Senhor, estas coisas não têm mais poder sobre nós' (Mocidade, junho de 1960). Essa e outras declarações abalaram os alicerces da velha ênfase da pregação moralista da Igreja. Não podiam ser lidas pelos crentes de uma grei de um século de vida eclesiástica (Araújo, 2002, 40).

A partir dos anos 60 , começou, em quase todos os países da América Latina, uma crescente conscientização acerca dos reais mecanismos produtores do 
subdesenvolvimento. O sujeito histórico de libertação seria o povo oprimido que deveria articular práticas que intencionassem e apontassem para uma sociedade alternativa menos dependente e injusta (BOFF, 1984, p. 24). Ainda segundo Boff (2011), os pobres, aqui, não são aqueles que possuem carências; eles as têm, mas possuem também força histórica, capacidade de mudança. Não se trata aqui de uma Igreja para os pobres, mas de uma Igreja de pobres e com os pobres (BOFF, 1984). A Igreja brasileira deu-se conta de que não há apenas o mundo moderno com seu desenvolvimento, mas um verdadeiro mundo com seu subdesenvolvimento e esse subdesenvolvimento representa o sofrimento para milhões de pessoas.

O envolvimento da Igreja com a questão social vinha se organizando em boa parte do mundo católico, mesmo dentro da doutrina social da Igreja, mas, em 1968, durante a Conferência do Episcopado Latino Americano, em Medellin, esse envolvimento ficou mais sistematizado com uma diretriz: a opção preferencial pelos pobres. Embora seja menos conhecido, fato é que a Teologia da Libertação não é um movimento teológico que pertenceu e pertence somente à Igreja Católica Romana. Tal movimento teológico ultrapassou a barreira denominacional e fez e faz parte do mundo Protestante de igual modo. Se de um lado a Igreja Católica se organizava e produzia documentos conforme citado (Medellin), do outro lado também os Protestantes históricos se organizavam dentro de suas estruturas eclesiais e eclesiásticas. De acordo com Joanildo Burity,

a Conferência contou com 167 participantes, representando 14 diferentes denominações protestantes (entre as quais batistas, congregacionais, presbiterianos, episcopais, luteranos, pentecostais, reformados, metodistas livres) e delegados de cinco igrejas dos Estados Unidos, México e Uruguai, como observadores. Dezessete estados do país, incluindo Pernambuco, estavam representados. Foi, realmente, a maior e mais significativa das promoções do SRSI, e também a última, já que, em 1964, logo aos o golpe militar, o departamento foi extinto pela CEB (BURITY, 2011, p. 172).

Luiz Ernesto Guimarães, em seu artigo intitulado: "A Teologia da Libertação sob o Viés Protestante" escreveu: 
Assim, a Conferência do Nordeste, juntamente com outros eventos formulados pelo protestantismo latino-americano, serviu de apoio e fomentou 0 desenvolvimento do pensamento social cristão (CAVALCANTI, 2012). No entanto, a Teologia da Libertação não foi o único resultado desse processo ocorrido nos setores progressistas. Outros movimentos, correntes e organizações também foram sendo desenvolvidas. Como exemplo, temos: Fraternidade Teológica LatinoAmericana ( $F T L)$, Aliança Bíblica Universitária (ABU), Visão Mundial etc (GUIMARÃES, 2012, p. 940).

Nomes como Rubem Alves, Paulo Stuart Wright, irmão do Reverendo Jaime Wright, pertencem à sujeitos que tiveram uma atuação marcante nos anos de ditadura militar e não podem deixar de ser mencionados quando se discute sobre esse período. A exemplo de um trabalho ecumênico na linha da Teologia da Libertação, o que comprova que tal Teologia não pertenceu somente à Igreja Católica, foi o trabalho desenvolvido em parceria entre o então Cardeal Dom Paulo Evaristo Arns com o Reverendo James Wright, nos anos da ditadura militar.

\section{PRESSUPOSTOS TEÓRICOS E TEOLÓGICOS DA TEOLOGIA DA LIBERTAÇÃO}

Boff (1980) acrescenta, em Teologia do Cativeiro e da Libertação, que o Cristianismo é uma práxis de libertação. A libertação é um conceito político (BOFF, 1980, p. 3). Considera a libertação humana como antecipação da salvação final. É o que se chama em Teologia do já e ainda não, ou seja, a libertação das estruturas injustas e de morte devem acontecer, pois o Cristo Libertador está presente através do seu Santo Espírito na luta do seu povo, com vistas a encorajar a luta contra o desânimo, mantendo-se, dessa forma, no caminho rumo à libertação prometida. Por outro lado, é o ainda não, pois a Teologia cristã tradicional também crê que a libertação última ocorrerá apenas no final dos tempos, em que seremos tudo em todos e teremos um só pastor para todo o rebanho $(2$ Cor 5,10$)$. 
Contudo, deve-se ter um certo cuidado com essa interpretação da Teologia tradicional de uma libertação apenas no porvir. E aqui está uma chave de leitura muito importante para os teólogos (as) da libertação: a antecipação da libertação. Ela não é assunto apenas do céu, é assunto também da terra. Conformar-se em sofrer na terra para somente depois gozar o céu, definitivamente não é um olhar da Teologia da Libertação. Por esse motivo é que se deve pensar nos conceitos do já e do ainda não supracitados. De acordo com Renold Blank:

O primeiro que formulou de maneira radical este compromisso da escatologia com a realidade histórica de hoje foi o teólogo protestante Jüngen Moltmann. Na sua obra Teologia da esperança, publicada em 1968, traduzida para o português em 1971, podemos ler a seguinte constatação programática: "A escatologia cristã não fala do futuro. Ela tem seu ponto de partida numa determinada realidade histórica e prediz o futuro desta..." Com esse enfoque, supera-se o enfoque existencial de Bultmann. Ultrapassa-se também a fixação nas "últimas coisas" que marca tanto a escatologia neo-clássica. Em vez disso, o interesse volta para a antiga escatologia dos profetas. Volta àquela concepção esperançosa, conforme a qual Deus conduz este mundo no decorrer de seu processo histórico, rumo a uma finalidade última. A teologia da esperança situa o discurso escatológico de novo numa base histórica e concreta. Ela supera as tentações de um discurso dualista, influenciado por concepções gnósticas. Com este passo, a escatologia volta de sua posição marginal, que tinha tido dentro do discurso teológico, para um lugar central (BLANK, 2000, p. 113-114).

Desse modo, no que tange ao sistema opressor, a Teologia da Libertação, justamente por crer que devemos nos libertar, tem a sua crença motivada no Deus da Aliança, apresentando reflexões desde o Antigo Testamento (AT) que conduziu o seu povo à Terra Prometida (Êxodo 33, 3), por crer que devemos trabalhar para modificar esse mundo para que ele seja um lugar melhor para todos viverem. É ela que levanta uma forte crítica moral e social do capitalismo dependente, a partir das reflexões de 
Fuerbach e Marx, que, por sua vez, denunciam o papel alienante da religião. É conhecida a posição de Marx quanto a religião, pois, para ele, é o ópio do povo". Porém, pode-se questionar: seria a religião o ópio ou a salvação do povo oprimido? Bem, esta não é a discussão do presente artigo, mas fica a provocação.

Embora a Teologia da Libertação rejeitasse muitos dos preceitos marxistas, inclusive a frase supracitada, aceitava, contudo, a metodologia marxista como método de leitura da realidade social e histórica. Acrescente-se que o método da Teologia da Libertação é o método dialético expresso no VER-JULGAR-AGIR. Do ponto de vista dos pressupostos Teológicos, o ponto de partida da Teologia da Libertação é o antropocentrismo, pois o pobre é o centro de articulação temática da cristologia e da eclesiologia, segundo Boff e Boff em "Uma breve história da Teologia da Libertação" (BOFF; BOFF, 1980, p. 26). Ainda segundo eles, Deus não pode ser uma abstração teológica, pois o Deus Vivo e Verdadeiro é atuante na história.

Blank (2000), na mesma linha de raciocínio, argumenta que este Deus da vida, por último, toma partido de maneira muito acentuada em favor de todos aqueles cuja vida está ameaçada. Ele se autotutela "go'él", o defensor daqueles que não têm defensor. O defensor do pobre, do fraco, do marginalizado, do excluído (Ex 3,7; 21,25-27; 22,20; 22,25; 23,6; 23,10; Lv 25,25). A Teologia da Libertação não se limita as deduções teóricas e não se deixa aprisionar ao modelo acadêmico de articulação teológica. Aliás, na Teologia da Libertação a questão de fundo não é a Teologia, mas a Libertação. Entende-se libertação concretamente, com o objetivo de acabar com o sistema de injustiça expresso no capitalismo, é libertar-se dele para criar em seu lugar uma nova sociedade (BOFF; BOFF, 1980, p. 70). E Moltmann diz:

Espera-se que "o homem de nosso tempo de novo se torne o receptáculo da influência de forças transcendentais". Está à procura de "ilhas de sentido" num mundo que, embora não seja sem sentido, é certamente não-humano (MOLTMANN, 1971, p. 372).

A Teologia da Libertação é um fenômeno complexo. Ela pretende dar uma nova interpretação global ao cristianismo. E, para alcançar esse objetivo, adota um método 
para analisar e interpretar a realidade. Método que se expressa na sigla VER JULGAR - AGIR e CELEBRAR. VER a realidade a partir da realidade mais crua e dura possível. Segundo Boff (2000), o VER suscita a compaixão que, por sua vez, leva à ira sagrada que impele a vontade de fazer alguma coisa para superar a situação.

Gutierres (1985) justifica essa proposição da Teologia da Libertação baseada no conceito Teológico de que Deus é Deus libertador e só se revela no conceito histórico concreto da libertação dos pobres e oprimidos (GUTIERREZ, 1985). Em suma, segundo Boff e Boff (1980), a Teologia da Libertação se concebe como uma nova hermenêutica da fé Cristã, como nova forma de compreensão de realização do Cristianismo em sua totalidade (BOFF; BOFF, 1980).

Para Moltmann (1971, p. 405): "nesta teologia, a fé cristã se torna transcendente frente a qualquer contexto socialmente experimentável. Não é demonstrável - na sua indemonstrabilidade está precisamente sua força, diz-se - e por isso também não é refutável". Assim, cabe aferir que a descrença, ainda conforme o autor, é o verdadeiro inimigo do ser humano, e, também, não deve ser posta como: "institucionalizável como reflexão continuada, sendo ela mesma transcendência frente às instituições sociais" (MOLTMANN, 1971, p. 405). A fé é responsável, dessa forma, pela transcendência humana.

\section{DECADÊNCIA E FUTURO DA TEOLOGIA DA LIBERTAÇÃO}

Quem melhor e com mais autoridade pode falar sobre decadência e o futuro da Teologia da Libertação é um dos mais representativos líderes da Teologia da Libertação no Brasil e na América Latina: Leonardo Boff. Em seu trabalho "Quarenta anos da Teologia da Libertação", com profundo pesar, de um lado, e com justificada esperança de continuidade, de outro, Boff reflete sobre o esfriamento do ânimo da Igreja Católica com as questões sociais. Elenca algumas das causas como a queda do marxismo na Europa e ditaduras da América Latina que deram vida às profundas mudanças na estrutura das Igrejas. O ímpeto de oposição ao poder autoritário arrefeceu. Aquele impulso de renovação do sentido e das tradicionais práticas 
religiosas acarretou a proposta de contrapor a Igreja hierarquia à nascente Igreja Povo de Deus e contrapôs-se a Igreja Poder à Igreja Comunhão.

A questão dos pobres e da pobreza, tanto na igreja como na sociedade política, retornou ao que era antes: o assistencialismo. O pobre reduzido a objeto de assistência e caridade. Volta-se à concepção do pobre como aquele que não tem e, por isso, ele não é. Ao contrário da concepção da Teologia da Libertação, em que o pobre é aquele que tem força do trabalho, capacidade de aprendizado e capacidade de reorganizar e lutar pelos seus direitos e ingressar no mercado de trabalho, desde que Ihe ofereçam oportunidades de aprender. Portanto, o pobre tem força histórica para mudar o sistema de dominação. Um pobre diferente que não quer apenas receber, mas que pensa, fala, que se organiza, que ajuda a construir um novo modelo de igreja - rede - de comunidades é o enfatizado pela teoria.

A esperança cristã, ao se opor àquelas orientações na história da humanidade, também não pode endurecer-se no passado e no presente dado, e assim aliar-se à utopia do status quo. É chamada e capacitada para a transformação criadora da realidade, pois possui uma perspectiva que se refere a toda a realidade. Tudo considerado, a esperança da fé se pode tornar uma fonte inesgotável para a imaginação criadora e inventora do amor. Ele provoca e produz perenemente ideais antecipatórios de amor em favor do homem e da terra, modelando ao mesmo tempo as novas possibilidades emergentes à luz do futuro prometido, e procurando, na medida do possível, criar o melhor mundo possível, porque o que está prometido é possibilidade total. Ela, por conseguinte, sempre desperta a "paixão do possível", os dons inventivos, a elasticidade nas transformações, a irrupção da novidade depois do velho, o engajamento do novo. A esperança cristã, neste sentido, sempre foi revolucionariamente ativa no decurso da história das ideias nas sociedades que por ela foram impregnadas (MOLTMANN, 1971, p. 25). 
Entretanto, isso não perdurou por muito tempo. A partir dos anos 70, o Vaticano passou agir de forma a "suavizar", diz Boff (1984), as posturas dos religiosos mais engajados socialmente. A justificativa desse suavização era a perseguição que os religiosos sofriam por parte dos militares, bem como os casos de torturas e violência que marcaram o período em que o Estado brasileiro esteve nas mãos dos militares. Ainda segundo Boff (1984), com o fim do regime militar, de acordo com a postura conservadora o Vaticano, toda essa suavização não mais se justificava. Acrescentese a isso à atitude do Vaticano que, para esmorecer o ânimo dos defensores da intervenção da igreja na questão social, nomeou bispos conservadores não comprometidos com a questão social nas principais dioceses.

Um dos inimigos da Teologia da Libertação, sem dúvida, foi o cardeal Joseph Ratzinger, pois, para ele, a Teologia da Libertação não cabe nos esquemas teológicos da sã e clássica teologia católica. Não há como aceitar uma teologia centralizada nas realidades terrestres, ignorando os fundamentos de séculos da teologia católica. Seria uma contradição aceitar uma teologia centralizada no pobre e na periferia da igreja e do mundo. Na condição de presidente da Congregação para a Doutrina da Fé, muitos teólogos foram postos por ele sob vigilância, advertidos, marginalizados em suas comunidades, acuados, proibidos de exercer o ministério da Palavra, afastados de suas cátedras ou submetidos a processos doutrinais com o chamado "silêncio obsequioso", conforme relata Boff (2011).

A obra de Ratzinger também proibiu mais de cem teólogos de todo o continente que elaborassem uma coleção de mais de 537 tomos da Teologia da Libertação como subsídio à estudantes e agentes de pastoral que atuavam na perspectiva dos pobres. Os estudiosos da Teologia da Libertação se perguntam hoje: que futuro tem a Teologia da Libertação? Sobretudo dentro do tipo de Igreja instituição que temos ela se centraliza na hierarquia como poder sagrado. Boff (2011), alude que ela só pode ser uma teologia do Cativeiro e revelada à marginalidade. Ao optar pelo poder, a Igrejainstituição optou por aqueles que também têm poder, numa palavra, os ricos. Os pobres perderam a centralidade. A eles está reservada a assistência e a caridade. Do 
mesmo modo que ocorreu o silenciamento dos teólogos da libertação no seio da Igreja Católica, tal fenômeno também ocorreu entre os protestantes.

O período da produção de sua tese e de sua publicação - 1969 - é importante para se pensar a ênfase que Rubem Alves coloca sobre a política. Afinal, não somente o Brasil, mas muitos países da América Latina viviam em grande efervescência política e social, causadas pela tomada de poder por governos ditatoriais. A supressão de movimentos democráticos e o tolhimento da liberdade de expressão provocaram, no continente, uma onda de terror e medo; quem se opusesse a tais lideranças governistas ficava completamente vulnerável, sem quaisquer direitos assegurados, correndo até mesmo o risco de morrer - ou "desaparecer" (GUIMARÃES, 2012, p. 941).

Mas, nem tudo está perdido. Embora não se apresente como "Teologia da Libertação", as raízes deles continuam presentes e produzindo resultados. Ela não se encontra explicitamente nas faculdades e institutos de Teologia. Ela continua viva nas bases, na leitura da Bíblia, nos círculos bíblicos, nas comunidades eclesiais de base, nas pastorais, nos movimentos de Fé e política e nos trabalhos pastorais na periferia, conforme Boff (2011). A Teologia da Libertação tem o futuro que está reservado aos pobres e oprimidos.

\section{CONSIDERAÇÕES FINAIS}

Cremos ter atingido o objetivo proposto na introdução, o de apresentar, de forma suscinta, o panorama da Teologia da Libertação no contexto da América Latina, onde mais fervilhou tal movimento a partir de 1950. Conforme dito e reafirmamos, o presente artigo teve a pretensão de ser apenas uma provocação ao aprofundamento do tema tão caro a nós e a tantos, dada a sua complexidade, ou seja, trata-se apenas de um lançar a semente com a esperança que ela caia em terra boa e, então, produza bons frutos. Conforme mencionado, tal movimento teológico não foi monopólio apenas da Igreja Católica Romana, mas também diversas Igrejas Protestantes se envolveram 
tendo seus expoentes, alguns deles mais conhecidos e mencionados no decorrer do artigo.

Tal fato para nós é motivo de alegria, afinal o Evangelho é de todas as denominações e de todas as pessoas que o adotem como manual de fé e conduta de vida. Outro ponto comum que merece destaque nessas considerações finais é que do mesmo modo que os teólogos e teólogas da libertação católicos foram silenciados com o tempo por seu modus procedendi, do mesmo modo, também, os teólogos e teólogas protestantes foram silenciados, quer sejam clérigos (as) ou leigos (as). Tal fato, apesar de ser um mal sinal, é, ao mesmo tempo, um bom sinal, afinal a voz profética sempre incomodou e continuará incomodando e esse definitivamente é um bom sinal. Pensar em tais questões é refletir sobre a o mundo moderno, o que justifica a relevância da proposta.

\section{REFERÊNCIAS}

ALTMANN, W. Teologia da libertação. Estudos Teológicos, v. 19, n. 1, p. 27-35, 1979.

BEZERRA, E. A.; DELGADO, L. de. A. N.; OLIVEIRA, V. C. J. de. Do humanismo cristão à práxis política de oposição a ditadura: memória de uma experiência dominicana". Disponível em: www.fiocruz.br/ehosudeste/cgi/cgilua.exe/sys/start.htm?siol=16. Acesso em: 01 out. 2014

BLANK, R. Escatologia da pessoa: vida, morte e ressurreição. (Escatologia I). São Paulo: Paulus, 2000.

BLANK, R. Escatologia do mundo: o projeto cósmico de Deus. (Escatologia II). São Paulo: Paulus, 2001.

BOFF, L. Quarenta anos da teologia da libertação. Petrópolis: Vozes, 2011. , L. Igreja: Carisma e poder. São Paulo: Ática, 1994. 
, L. Jesus Cristo Libertador. Petrópolis: Vozes, 1975.

, L. Teologia do Cativeiro e da Libertação. Petrópolis: Vozes, 1980.

,L. Saber Cuidar. Petrópolis: Vozes, 1999.

BOFF, L.; REGIDOR, J. R.; BOFF, C. A teologia da Libertação: balanços e perspectivas. São Paulo: Ática, 1996.

CATÃO, F. A. C. O que é Teologia da Libertação. São Paulo: Brasiliense, 1986.

DELGADO, L. de. A. N.; PASSOS, M. "Catolicismo: direitos sociais e direitos humanos (1960-1970)". In: FERREIRA, J.; DELGADO, L. de. A. N. (orgs.). O Brasil Republicano. Volume 4: O tempo da ditadura: Regime militar e movimentos sociais em fins do século XX. Rio de Janeiro: Civilização Brasileira, 2003.

GUIMARÃES, L. E. A Teologia da Libertação sob o viés protestante. In: IX SEPECH, p. 933-947, 2012.

GUTIERREZ, G. Teologia da Libertação. Petrópolis: Vozes,1985.

LOVATO, F. F. de A. A Teologia da Libertação na América Latina e suas manifestações em Santa Maria- RS. In: QUEVEDO, J.; IOKOI, Z. M. G. (orgs.). Movimentos Sociais na América Latina: desafios teóricos em tempos de globalização. Santa Maria: MILA-CCSH, 2007.

MOLTMANN, J. Teologia da esperança: estudos sobre os fundamentos e as consequências de uma escatologia cristã. São Paulo: Herder, 1971

MONDIN, B. Os teólogos da libertação. São Paulo: Paulinas, 1980.

REGAN, D. Igreja para a Libertação: Retrato pastoral da Igreja no Brasil. São Paulo: Paulinas, 1986.

ROUQUIÉ, A. Igreja e Igrejas. In: 0 extremo-ocidente: introdução à América Latina. São Paulo: EDUSP, 1991. 
SCHMITT, C. O Conceito de Político. Petrópolis: Vozes, 1992.

SOBRINO, J. Jesus, o Libertador. São Paulo: Vozes, 1994.

\section{APÊNDICE - REFERÊNCIAS DE NOTA DE RODAPÉ}

3. Quando se fala em Cristo Pantocrator, logo de pensa na figura iconográfica (tradição bizantina) de Cristo Imperador do Cosmos. É na teologia ortodoxa onde se encontra tal ênfase cultica e iconográfica, ou ainda nas igrejas de tradição oriental, tal a como a Igreja Melquita, por exemplo, sendo essa parte da Igreja Católica Romana. E aqui quando se fala em Teologia Ortodoxa faz-se uma referência à Liturgia Ortodoxa, à Missa propriamente dita, pois é nesta liturgia onde se expressa toda a grandeza do culto e do louvor que se deve prestar a Deus através do Cristo Imperador do Cosmos. "A esse tipo de imagem de Cristo é dado o nome genérico de «Pantocrator» tão rico de significados. O termo grego, traduzido geralmente por «Onipotente», mas que é melhor traduzir pela expressão "Oniregente», ou «Aquele que tudo rege", é um termo que se encontra já na literatura pagã. É encontrado na versão grega dos Setenta que o retoma para traduzir a expressão "Sabaoth», conferindo-Ihe o significado de Deus «Dominador de todas as potências terrestres e celestes.

Disponível

em:

https://www.ecclesia.com.br/biblioteca/iconografia/o_tipo_iconografico_do_pantokrat or.html._Acesso em 01 mar. 2020.

4. Um dos principais teólogos latino-americanos e um dos expoentes da Teologia da Libertação, Gustavo Gutiérrez ingressou, em 1947, na Universidade Nacional Maior de São Marcos (UNMSM), onde estudou quatro anos de medicina. Ao mesmo tempo, fez o curso de Letras na Pontifícia Universidade Católica do Peru. Nesses anos participou, como laico, na Ação Católica. De 1951 a 1955, estudou filosofia e psicologia na Universidade Católica de Louvain (Bélgica) e se graduou em psicologia. De 1955 a 1959, estudou teologia na Universidade Católica de Lyon (França) - onde obteria, em 1985, seu doutorado em teologia - e de 1959 a 1960, na Universidade Gregoriana, em Roma. Entre 1962 e 1963, estudou no Institut Catholique, em Paris. Gutiérrez ordenou-se sacerdote em 1959. No ano seguinte, quando de seu regresso 
ao Peru, assumiu a assessoria da União Nacional de Estudantes Católicos (UNEC), que posteriormente daria origem ao Movimento de Profissionais Católicos, ambos vinculados ao movimento internacional católico de estudantes e de intelectuais Pax Romana. Ainda em 1960, passou a ensinar na Pontifícia Universidade Católica, de cujo Departamento de Teologia foi professor principal. Seus cursos na Faculdade de Letras e depois na de Ciências Sociais entabulavam um diálogo entre a fé cristã e o pensamento contemporâneo. No início dos anos 1960, ele assistiu, como assessor teológico do Monsenhor Manuel Larraín do Chile, ao Concílio Vaticano II. Posteriormente, participou das preparações dos diversos Departamentos do Conselho Episcopal Latino-americano (CELAM), da II Conferência Geral do Episcopado Latinoamericano, em Medellín (Colômbia), em 1968, à qual compareceu como perito teológico. De 1967 a 1979, foi membro da Equipe de Reflexão Teológica do CELAM e, de 1968 a 1980, integrou a Equipe de Reflexão Teológica da Conferência Episcopal Peruana. Em 1979, foi também assessor de vários bispos latino-americanos na II Conferência Geral do Episcopado Latino-americano, em Puebla (México).

Enviado: Março, 2020.

Aprovado: Maio, 2020. 